\title{
Prospects of Organic Conducting Polymer Modified Electrodes: Enzymosensors
}

\author{
Ravindra P. Singh \\ Nanotechnology Application Centre, University of Allahabad, Allahabad 211002, India \\ Correspondence should be addressed to Ravindra P. Singh, rpsnpl69@gmail.com \\ Received 31 July 2011; Accepted 2 January 2012 \\ Academic Editor: Benjamín R. Scharifker
}

Copyright () 2012 Ravindra P. Singh. This is an open access article distributed under the Creative Commons Attribution License, which permits unrestricted use, distribution, and reproduction in any medium, provided the original work is properly cited.

Organic conducting polymer modified electrodes (OCPMEs) have emerged as potential candidates for electrochemical biosensors due to their easy preparation methods along with unique properties, like stability in air and being compatible with biological molecules in a neutral aqueous solution. OCPMEs are playing an important role in the improvement of public health and environment for the detection of desired analytes with high sensitivity and specificity. In this paper, we highlight the prospects of OCMEs-based electrochemical enzymosensors.

\section{Introduction}

Various methods used for the determination of a variety of desired analytes (without use of biocatalyst) are gas chromatography, colorimetric and flourimetric analysis, and so forth. However, these methods need sample pretreatment which stands as a major disadvantage in their versatility of applications. These methods cannot be used for field monitoring. Thus, devices were developed based on biocatalyst to analyze desired analytes of interest known as biosensors, which are of vital importance. Many biosensors have been developed for the determination of analytes in the biological samples, namely, spectrometry, potentiometry with application of $\mathrm{pH}$ sensitive electrode or an ion selective electrode or an ion sensitive field effective transistor, conductometry, coulometry, amperometry, and inductometry [1-13].

Biosensor is an analytical device, which incorporates biological sensing elements like enzymes, antibodies, receptors, aptamers, nucleic acids, cells, and so forth over electrodes. Electrode decides the sensitivity, selectivity, and reproducibility of the sensor/biosensor, with electronic transducer equipped with an electronic amplifier and was found to have applications in various fields, for example, clinical diagnostics, environmental monitoring, bioprocess monitoring, food, agricultural product processing, and so forth $[14,15]$. According to IUPAC, biosensor specifically defined as a self-contained integral device that is capable of providing specific quantitative or semiquantitative analytical information using a biological element [16]. Biosensor has three major components: (a) biorecognition element or bioreceptor, (b) an immobilization surface for immobilization of biomolecule, and (c) a transducer unit for conversion of biochemical reaction product into a recognizable signal. Thus, bioreceptor and transducer together may be referred to as biosensor membrane $[17,18]$. The history of biosensor started in 1962 with the development of first enzyme-based glucose sensing device by Clark and Lyons using a thin layer of glucose oxidase (GOx) entrapped over an oxygen electrode via semipermeable dialysis membrane for the measurements of the $\mathrm{O}_{2}$ consumed by the enzyme-catalyzed reaction [19]. Nowadays, biosensors are much more advanced than the Clark enzyme electrode, but are facing new challenges like the instability of desired biomolecules with an electrode. The redox reaction in terms of measuring the loss or formation of substrate or product, the use of a small mediator species that shuttles between the biomolecule and the electrode, or direct electron transfer (ET) between the biomolecule redox site and the electrode. Direct ET can be difficult to achieve, since the redox site of a biomolecule often buried deep inside the biomolecule. The modification of biomolecules or electrode surfaces using novel conducting materials as mediators and design of functional biointerfaces. Thus, highly conductive 
organic transducers like CPs nanomaterials, sol-gel films, and self-assembled monolayers, and so forth are gradually emerging for the development of next-generation biosensor design for highly reliable, stable, and robust field-based biosensor devices [20, 21].

Chemical bonding in conducting polymers provides one unpaired electron, that is, $\pi$-electron per carbon atom in the backbone of the polymer. Carbon atoms are in $\mathrm{sp}^{2} \mathrm{p}_{z}$ configuration in $\pi$-bonding and orbitals of successive carbon atoms overlap providing delocalization of electrons along the backbone of polymer. This delocalization provides the charge mobility along the backbone of the polymer chain and induces unusual properties such as electrical conductivity, low ionization potential, low energy optical transitions, and high electron affinity. The $\pi$ bonds in conjugated polymers are highly susceptible to chemical or electrochemical oxidation or reduction. The origin of electrical conduction in conducting polymers has been ascribed to the formation of nonlinear defects such as solitons, polarons, or bipolarons formed during either doping or polymerization of a monomer. The conductive and semiconducting properties of these polymers make them an important class of materials for a wide range of electronic, optoelectronic, and biotechnological applications such as in rechargeable batteries, molecular electronics, electronic displays, solar cells, ion exchange membrane in fuel cells, diodes, capacitors, field-effect-transistors, printed circuit boards, chemical sensors, drug release systems, and biosensors. Conducting polymers can be used to transport small electronic signals in the body, that is, act as artificial nerves. Scientists have used films in a neurotransmitter as a drug release system into the brain [22-28].

The most commonly used organic conducting polymers and their potential applications are reported in the literature, including poly(acetylene)s, poly(pyrrole)s, poly(thiophene)s, poly(terthiophene)s, poly(aniline)s, poly(fluorine)s, poly(3-alkylthiophene)s, polytetrathiafulvalenes, polynapthalenes, poly(p-phenylene sulfide), poly(paraphenylenevinylene)s, poly(3,4-ethylenedioxythiophene), polyfuran, polyindole, and polycarbazole. The polymer growth and stability are of the most important criteria for the stable device development. The growths and stabilities of poly(aniline)s, poly(pyrrole)s, and poly(azulene)s have been reported. Poly(thiophene)s shows excellent thermal and air stability, solubility, processability, and high conductivity when compared to other important class of conducting polymers. Conducting polymers can be reversibly doped and undoped using electrochemical techniques accompanied by significant changes in conductivity. The electrical conductivity of conducting polymers changes over several orders of magnitude in response to change in $\mathrm{pH}$, applied potentials, or their environments. Grafting of organometallics to the backbone of the conducting polymer can also tune their physical properties. Potential applications of the conducting polymers have been reported in the development of sensors/biosensors, and emerged as one of the unique materials for the fabrication of electrochemical devices with improved response properties, including sensitivity and selectivity due to their electrical conductivity or charge transport properties and biocompatibility. However, conducting polymer itself could be modified with biomolecules and acts as a biosensor. In addition, conducting polymers via electrochemical synthesis allows direct deposition of a polymer film on the electrode substrate followed by biomolecules immobilization. Thus, it is not only possible to control the immobilized biomolecules and film thickness but also to act as an electron promoter [29-39] as shown in Figure 1.

Ramaniviciene and Ramanavicius have reported an interesting review on the potential use of conducting polymers as electrochemical-based biosensors [40]. Malinauskas et al. have described the electrochemical aspects of conducting polymer based nanostructured materials for application to supercapacitors, energy conversion systems, batteries, and sensors [41]. Schuhmann et al. reported that functionalization of conducting polypyrrole films provides suitable surface for covalent linkage of enzymes after carbodiimide activation [42]. Gorton et al. have described the role of direct electron transfer between hemecontaining enzymes and electrodes as the basis of third-generation biosensors [43]. Schuhmann has classified biosensors based on (i) electron-transfer via conducting polymers, (ii) electrontransfer cascades via redox hydrogels, (iii) anisotropic orientation of redox proteins, and (iv) direct electron transfer between redox proteins and electrodes modified with selfassembled monolayers [44]. The interest in nanomaterials for biosensing applications has recently emerged. The sizedependent changes in the physical and chemical properties of materials make them different from that of their bulk counterpart. The change in physical properties makes nanomaterials an important candidate for technological development of biodevices. The large surface-to-volume ratio provides substantial changes in chemical properties. The fullerenes and carbon nanotubes can be a class of conjugated polymers due to semiconducting nature as well as possibility of p-type and n-type doping which can be made possible due to the presence of conjugated carbon structure with unusual molecular symmetries which makes them compatible with conducting polymers and promising materials from technological point of view. Ramanathan et al. have functionalized single wall carbon nanotubes with amino groups, which may covalently attach to polymers or biological systems such as DNA and carbohydrates [45]. Carrara et al. have utilized improved nanocomposite materials of poly (o-anisidine) (POA) containing titanium dioxide nanoparticles $\left(\mathrm{TiO}_{2}\right)$, carbon black, and multiwalled carbon nanotubes (MWNT) for biosensing applications based on electrochemical impedance spectroscopy [46]. Anzai et al. have described various techniques for the surface derivatization within biotin and avidin and for the coupling of the enzymes [47]. Nobs et al. have covalently bound NeutrAvidin to the surface of poly(dL-lactic acid) (PLA) nanoparticles with the aim of attaching targeting compounds such as proteins and other proteins such as antibodies could be coupled to the nanoparticles for active targeting. Furthermore, PLA nanoparticles are interesting candidates for active targeting with biotinylated antibodies using the biotin-avidin interaction in a two-step procedure [48]. Gref 


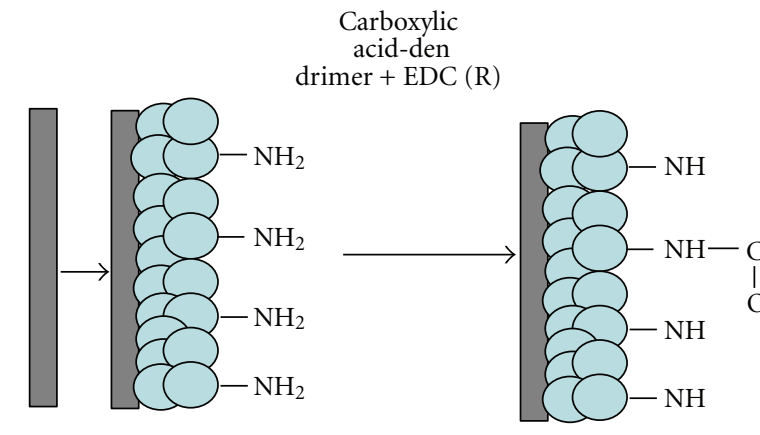

Electropolymerization
Covalent bonding between polymer and dendrimer

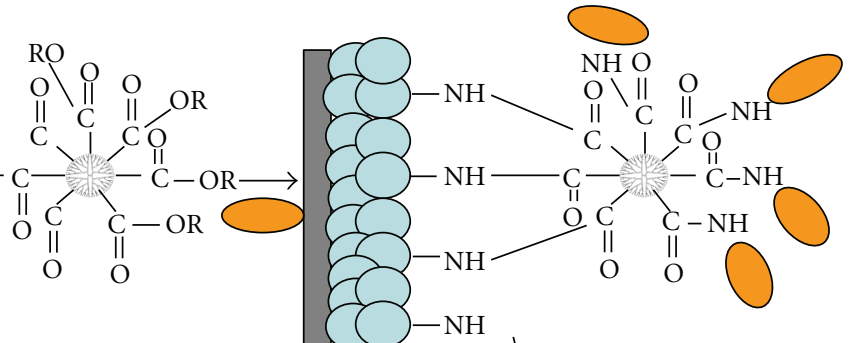

Electrochemical biosensing

Covalent bonding between dendrimer and enzyme

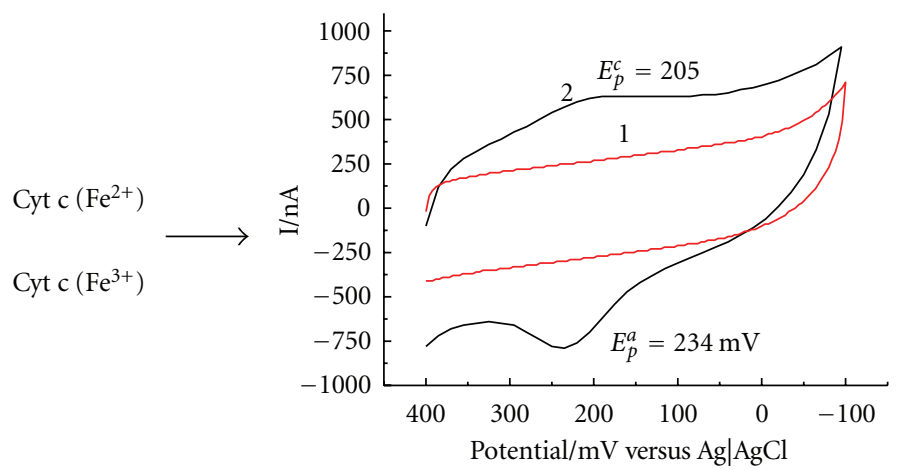

Dendrimer

Enzyme

Conducting polymer

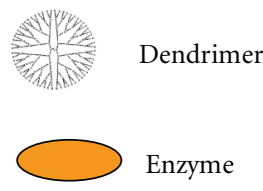

FIGURE 1: Shows the schematic presentation of enzymosensor using organic conducting polymer.

et al. have shown that biotin-poly(ethylene glycol)-poly $(\beta-$ caprolactone) (B-PEG-PCL) can be helpful for studying the interaction between cells and functionalized nanoparticles with surface characteristics (ligand type and density, PEG layer density, and thickness) [49].

\section{Enzymosensors}

Enzymatic biosensors utilize the biospecificity of an enzymatic reaction, along with an electrode reaction that generates an electric current or potential difference for quantitative analysis. The biomolecules such as glucose, cholesterol, urea, triglycerides, creatinines, and pesticides are important analytes due to their adverse effects on health. Enzymatic biosensors utilize the biochemical reactions, that is, analyte and enzyme resulting in a product (hydrogen/hydrogen peroxide/hydroxyl/ammonium ion), that can be detected and quantified using a transducer (amperometric/potentiometric/optical thermal/piezoelectric). In general, many oxidoreductases including glucose oxidase catalyze the oxidation of substrates by electron transfer to oxygen to form hydrogen peroxide. These oxidoreductase enzymes immobilized on conducting polymer surfaces, the $\mathrm{H}_{2} \mathrm{O}_{2}$ formed because of enzyme, and the corresponding analytes may be measured amperometrically. However, it has not been possible to discriminate between the direct electron transfers from the oxidation of hydrogen peroxide at polymer surface and that at the underlying electrode. Since conducting polymers are insoluble in aqueous solutions, electropolymerization are used to create a matrix for immobilization of enzymes at the electrode surface, and the sensor response obtained by the oxidation of hydrogen peroxide [50-57].

Measurement of a target analyte could be achieved by selectively converting molecular recognition occurring at analyte sensor interface from a nonelectrical domain to an electrical signal. The PANI in sensing due to its ability to reversibly oxidized and reduced through the application of electrical potential and electrical conduction in PANI is achieved through the formation of defects in the polaronic (one hole state) and bipolaronic forms (two hole state). When exposed to analytes, stoichiometry of the existing PANI energy levels is disturbed through the substitution of different species into the polymer lattice and causes a change in the electrical conductivity. The fabrication 
of PANI-based electrode for biosensor application for its commercialization is a major challenge due to the aging effect, low electrochemical stability, and lack of deposition techniques. Wolter et al. have reported the continuous decrease in conductivity of PANI, which in turn influences its charge transfer properties and electrochemical stability, because of the oxidation/reduction of soluble electrochemical degradation products, including p-benzoquinone (PBQ) [58]. Rahmanifar et al. have speculated the formation of PBQ, which initiates cross-linking reaction between linear polymer chains that interrupts the delocalization of both the charge and electrons along the polymer chain leading to the decrease in conductivity and charge transfer of PANI [59]. Chandrakanthi and Careem have claimed that PANI has the highest environmental stability [60] and recognised as the only conducting polymer that is stable in air reported by Sergeyeva et al. [61]. Luo and Do have reported PANI as an interesting material for sensor and biosensor interfaces since it acts as an effective mediator for electron transfer in redox or enzymatic reactions and can be used as a suitable matrix for immobilization of biomolecules [62]. Polyaniline is a semiflexible conducting polymer family due to its high conductivity and low cost, targeting for its applications in biosensors because of a number of useful properties such as direct and easy deposition onto the electrode, control of thickness, redox conductivity and polyelectrolyte characteristics, high surface area, chemical specificities, longterm environmental stability, and tuneable properties. An advantage of PANI in the field of biosensor are an impressive signal amplification and elimination of electrode fouling and exhibits two redox couples in the convenient potential range to facilitate an efficient enzyme-polymer charge transfer. Iribe and Suzuki have demonstrated the use of polyaniline as an enzyme switch, which yields "on" and "off" responses. PANI consists of reduced (benzenoid diamine) and oxidised (quinoid diamine) repeating units. The different redox forms of PANI are reported. Leucoemeraldine (LE) is fully reduced state. Pernigraniline (PG) is fully oxidized state with imine links instead of amine links. The emeraldine form of PANI, often referred to as emeraldine base (EB), is either neutral or doped, with imine nitrogens protonated by an acid. EB is regarded as the most useful form of PANI due to its high stability at room temperature and that its doped form (emeraldine salt; ES) is electrically conducting. LE and PG are poor conductors, even when doped with an acid. These forms have interconverted by chemical and/or electrochemical oxidation or reduction. The delocalized $\pi$-bonds available in this system are responsible for its semiconducting properties. When PANI has doped with an acid, a polaron formed through successive formation of bipositive species, bipolaron structure, and more stable polaron structure. This polaron structure is responsible for electrical conduction through hopping mechanism in its crystalline region and this hopping may be intrachain or interchain. In polaron structure, a cation radical of one nitrogen acts as a hole and this hole acts as charge carriers. The electron from the adjacent nitrogen (neutral) jumps to this hole and it becomes electrically neutral. Then, the holes start to move. In bipolaron structure, this type of movement is not possible since two holes are adjacently located. In LE or PN structures, the electronic environments of all nitrogen atoms along the polymer chain are similar. Protons from a dopant can be attracted by any nitrogen atom and there may be a few (more than two) protonated nitrogen or free nitrogen atoms situated side by side across the chain. There is a less chance for chain regularity, creating less chance for the formation of a polaron. As a result, protonated LE or $\mathrm{PN}$ are insulating in nature. PANI's transport properties, electrical conductivity, or rate of energy migration, provide enhanced sensitivity. It is the best-known semiflexible rod CP system with chemical and structural flexibility surrounding its amine nitrogen linkages for effective binding and immobilization of biomolecules [63]. Besides this, Ding et al. have reported control over the shape and dimensions of PANI by varying synthesis or processing conditions is likely to result in desired physical and electrochemical properties for biosensing application [64]. Forzani et al. have reported nanostructures of PANI, for example, nanowires, nanospheres, nanorods, and nanotubes which have provided a new ground to improve its characteristics and offer the possibility of enhanced performance wherever a high interfacial area between PANI and its environment is important [65]. The morphology of nanostructured PANI plays an active role in enhancement of activity of desired catalyst. Sreedhar et al. have recently studied the activity profile of the oxidation of 4-bromothioanisole using PANI nanospheres (S), nanorods ( $\mathrm{R})$, nanotubes $(\mathrm{T})$. These investigations have revealed that the activity varies as $\mathrm{S}<\mathrm{R}<\mathrm{T}$, that has been attributed to enhanced surface area in case of PANI nanotubes (PANI-NT) [66]. The integration of nanostructures and biomolecules may lead to new hybrid systems that couple the recognition or catalytic properties of biomaterials with attractive electronic and structural characteristics. The use of PANI nanostructures also helps to overcome the processability issues associated with PANI. Mathebe et al. have fabricated $\mathrm{H}_{2} \mathrm{O}_{2}$ biosensor by immobilizing $\mathrm{HRP}$ on electropolymerized films of PANI by making use of electrostatic interactions between PANI backbone and enzyme. This electrochemically active PANI matrix serves as an efficient nondiffusional mediator, shuttling electrons between redox active centre of enzyme and the electrode surface [67]. Michira et al. have synthesized and characterized a novel anthracene sulfonic acid (ASA) doped PANI nanomaterial and have explored its application for amperometric biosensor for $\mathrm{H}_{2} \mathrm{O}_{2}$ and erythromycin. The studies reveal that this self-doped PANI/ASA matrix acts as an effective electron mediator as it provides direct electrical communication between the enzymes (HRP, cytochrome P450 3A4) and the platinum electrode [68]. Wang et al. have reported $\mathrm{H}_{2} \mathrm{O}_{2}$ biosensor constructed by cross-linking with HRP and PANI, electrochemically deposited in the presence of ionic liquid, using glutaraldehyde on F-doped tin oxide (FTO) [69]. Iwuoha et al. have examined amperometric behaviour of HRP in biosensor format where polyvinyl sulphonate (PVS) doped aniline, which electropolymerized onto the surface of glassy carbon electrode (GCE). Biomolecules are doped onto the polymer surface by electrostatic interactions with polymer backbone [70]. Kathleen et al. have reported 
the influence of the thickness of PANI film deposited electrochemically onto screen-printed electrode (SPE) surface has been described in terms of its influence on a variety of amperometric sensor characteristics like time to reach steady state, charging current, catalytic current, background current, and signal/background ratio [71]. Lyons et al. have reported the sensitivity and limit of detection of polymerbased biosensor are dependent on the background current exhibited by polymer [72]. Mu and Xue have reported that if the background current of a sensor based on these PANI/PVS films is too large, then the contribution from the reduction of $\mathrm{H}_{2} \mathrm{O}_{2}$ by $\mathrm{HRP}$ is difficult to measure. High background currents could limit the contribution from the enzyme catalytic reaction, thereby decreasing sensitivity of the sensor. Therefore, thinner polymer films are preferable, especially where lower levels of analytes are to be detected [73]. The good biocompatibility of PANI nanostructure enables it to become a simple and effective platform for the integration of proteins/enzymes and electrodes, providing analytical access to a large group of enzymes for a variety of bioelectrochemical applications. Morrin et al. have described fabrication of uniform array of nanoparticulate PANI nodules using dodecylbenzenesulfonic acid (DBSA) as dopant for $\mathrm{H}_{2} \mathrm{O}_{2}$ detection using $\mathrm{HRP}$ as biosensing element. This effective biosensor format exhibits higher signal-to-background ratio and shorter response time. The authors show a comparison between the characteristics of the optimized nanoPANI/DBSA film with that of PANI/PVS film in terms of a platform for biosensing. The results indicate nanoPANI/DBSA film is a more efficient matrix in terms of protein immobilization and require concentration of protein sixfold lower than PANI/PVS layer for monolayer coverage [74]. Luo et al. have prepared a highly nodular, cauliflower-like nanostructured electrode through the electropolymerization of aniline on SPE with subsequent deposition of polystyrene (PS) nanoparticle template and further growth of PANI around these templates. The high sensitivity of this biosensor is probably due to the unique nanostructure on the electrode surface, as the cauliflowerlike nanostructured PANI can contact with more enzyme molecules and thus can be more efficient in assisting electron transfer from the enzyme to the electrode surface [75]. Wang et al. have recently reported a glucose biosensor based on direct ET of GOx entrapped electrochemically into the inner wall of highly ordered PANI-NT synthesized using anodic aluminium oxide (AAO) as template. The direct ET from the GOx to the electrode $(\mathrm{Pt})$ indicated by the generation of a pair of well-defined symmetrical redox peaks in CV of GOx-PANI-NT/Pt [76]. Xu et al. have reported a novel glucose biosensor, with high sensitivity and selectivity, fabricated by self-assembling GOx and PtDENs on nanofibrous PANI. The resulting biosensor exhibits excellent amperometric response to glucose and possesses biocompatible performance with the possibility of minimizing enzyme denaturing [77]. Xian et al. have reported the electrical contacting of gold nanoparticles (Au NP) with the glassy carbon through PANI nanofibers, which enables this nanocomposite structure to be used as an excellent matrix for electrocatalysis and enzyme (GOx) immobilization [78].
Zhou et al. have reported results of similar studies using platinum $(\mathrm{Pt})$ microparticles for glucose detection and found the bioelectrode to be highly stable and reproducible [79]. Ramanathan et al. have utilized Langmuir Blodgett (LB) films of PANI for a glucose biosensor fabrication [80]. Recently, Nemzer et al. have demonstrated the role of PANI both as host polymer and redox indicator for glucose oxidase. Thus, this smart material provides a biosensing route that eliminates the need of redox dyes during optical detection of glucose [81]. Borole et al. have reported a comparative study of glucose sensor by entrapping GOx in PANI, poly $(o-$ toluidine) (POT), and its copolymer. The amperometric response reveals that PANI-GOx electrode is much more preferable for use because of the comparatively fast response [82]. Xue et al. have developed a new glucose biosensor by in situ electropolymerization of aniline into microporous PANI-coated platinum electrode in the presence of GOx. The technology combines the advantage of microporous polymer material and electropolymerization in biosensor construction. Thus, prepared bioelectrode exhibits good selectivity, sensitivity, stability, and shows no apparent loss of activity after 100 consecutive measurements and intermittent usage for 100 days [83]. Shi et al. have reported that poly(aniline-boronic acid) wires generated on double standard DNA (dsDNA) template could facilitate electrical communication between electrode and GOx reconstituted on polymer wires. However, the operating potential for detection of glucose at this electrode is $+0.5 \mathrm{~V}$ (versus SCE) and at this potential many other electroactive species commonly coexisting in biological fluids, such as ascorbic acid, uric acid, and 4-acetamidophenol, can get oxidized and severely affect the selectivity of sensors [84]. Zhao et al. have investigated PANI nanofibers as electrode material for direct ET of redox proteins/enzymes with GOx as a model. After immobilization on this nanofiber matrix, GOx remains in its natural structure and undergoes effective, direct ET reaction with a pair of well-defined, quasireversible redox peaks. The electrode displays good features in electrocatalytic oxidation of glucose with good reproducibility and stability [85]. Sukeerthi and Contractor have fabricated and compared the response of three different biosensor array structures of PANI [86], Contractor et al. have reported macrosensor (twinwire electrode configuration) [87], Sangodkar et al. reported microsensor [88] and microtubular sensors for glucose, triglyceride, and urea. This microtubular sensor found to have the highest sensitivity for all the three analytes. This enhanced sensing characteristic in case of PANI microtubules attributed to shorter source-to-drain distance and more disordered structure of PANI that result in increased conductivity, transduction ability, and supports effective enzyme loading. Karyakin et al. have explored the advantages of PANI as potentiometric transducer for detection of bioanalytes like glucose, urea, and so forth. The potentiometric detection of enzyme activity based on the measurement of change in $\mathrm{pH}$ in the enzymatic layer on sensor surface has caused by oxidation of $\mathrm{H}_{2} \mathrm{O}_{2}$ produced by the enzymatic reactions [89]. Gaikwad et al. have fabricated potentiometric glucose biosensor by immobilizing GOx on electrochemically synthesized PANI film via glutaraldehyde. This bioelectrode 
was found to perform well in terms of dynamic range of detection and short response time [90]. Wang and $\mathrm{Mu}$ have studied bioelectrochemical characteristics of $\mathrm{ChOx}$ immobilized onto an electrochemically deposited PANI film. These studies have revealed that the response current of the enzyme electrode at Triton X-100 concentration is of $1 \%$ [91]. Bayramoğlu et al. have proposed a new conductive fiber support based on PAN/PANI for immobilization of invertase enzyme and offers an economical protocol for reversible enzyme immobilization on conductive composite fiber [92]. Kim and Jeon have reported an amperometric superoxide microbiosensor by electropolymerization of aniline with concomitant doping of superoxide dismutase on the surface of Pt electrode. The amperometric response to superoxide anion was obtained at a potential of $0.75 \mathrm{~V}$ for oxidation of $\mathrm{H}_{2} \mathrm{O}_{2}$ generated from disproportionation of superoxide anion [93]. Shan et al. have developed a sensitive and stable amperometric phenol biosensor by coentrapping PPO with in situ polymerization of PANI in PAN matrix, and modified electrode was used to detect benzoic acid [94]. Castelletti et al. have developed a capillary electrophoresis (CE) biosensor for measuring ascorbic acid by coupling a PANI optical sensor and CE [95]. Langer et al. have developed a choline sensor by immobilization of choline oxidase (ChO) to nanoporous PANI layers [96]. Bartlett et al. have reported successful oxidation of NADH at PANIcoated electrode. The electropolymerization of PANI has accomplished in presence of PVS counter ions that gave rise to films that are both stable and electroactive at pH 7 [97]. Tian et al. have described an amperometric biosensor for the detection of $\mathrm{H}_{2} \mathrm{O}_{2}$ based on horseradish peroxidase/polypyrrole ( $\mathrm{PPy}$ ) membrane deposited onto the surface of ferrocenecarboxylic acid mediated derived sol-gel derived composite carbon electrode [98]. Yadav et al. have fabricated a highly sensitive, specific, and rapid electrochemical oxalate biosensor by covalently immobilizing sorghum leaf oxalate oxidase on carboxylated multiwalled carbon nanotubes and conducting polymer, polyaniline nanocomposite film electrodeposited over the surface of platinum $(\mathrm{Pt})$ wire using $\mathrm{N}$-ethyl- $\mathrm{N}^{\prime}$-(3-dimethylaminopropyl) carbodiimide (EDC) and N-hydroxy succinimide (NHS) chemistry [99]. Tang et al. have fabricated a novel $\mathrm{H}_{2} \mathrm{O}_{2}$ sensor based on enzymatically induced deposition of electroactive polyaniline (PANI) at horseradish peroxide (HRP)/aligned single-wall carbon nanotubes (SWCNTs) modified Au electrode. Thus, the synergistic performance of the enzyme, the highly efficient polymerization of PANI, and the templated deposition of SWCNTs provided an extensive platform for the design of novel electrochemical biosensors [100]. Chen et al. have fabricated multiwalled carbon nanotube (MWCNT)/polyaniline (PANI) composite film by electrochemical polymerization. The immobilized AChE catalyzed the hydrolysis of acetylthiocholine chloride to produce thiocholine, which engendered an irreversible oxidation peak. The enzyme activity was monitored by measuring the oxidation current of thiocholine and further detection of OP. The developed sensor provided a new promising tool for pesticide analysis and assay of enzyme activity [101]. Vatsyayan et al. have fabricated GCE/MWCNT-NF/CAT/PEI electrode for hydrogen peroxide $\left(\mathrm{H}_{2} \mathrm{O}_{2}\right)$ detection. Catalase (CAT) $(\mathrm{Mr} \sim 90 \mathrm{kDa})$, immobilized on multiwalled carbon nanotubes-Nafion (MWCNT-NF) matrix and encapsulated with polyethylenimine (PEI) on glassy carbon electrode (GCE), showed a pair of nearly reversible cyclic voltammetric peaks for $\mathrm{Fe}(\mathrm{III}) / \mathrm{Fe}(\mathrm{II})$ couple with formal potential of about $-0.45 \mathrm{~V}$ (versus $\mathrm{Ag} / \mathrm{AgCl}$ electrode at $\mathrm{pH}$ 7.5). PEI significantly reduced the charge transfer resistance and stabilized the bioelectrode through electrostatic interaction [102]. Rajesh et al. developed highly sensitive biosensor for the direct and simultaneous determination of superoxide anion radical $\left(\mathrm{O}^{2-}\right)$ and nitrite $\left(\mathrm{NO}^{2-}\right)$ by incorporation of carbon nanotube (CNT) solubilized in nafion in polypyrrole (PPy) matrix on Pt electrode followed by immobilization of $\mathrm{Cu}, \mathrm{ZnSOD}$ (SOD1) onto it. The modified electrode not only enhanced the immobilization of SOD1 but also promoted the electron transfer of SOD1 minimizing its fouling effect. This modified electrode is effective not only in detecting $\mathrm{O}^{2-}$ and $\mathrm{NO}^{2-}$ independently but also determining the concentration of $\mathrm{O}^{2-}$ and $\mathrm{NO}^{2-}$ simultaneously in vitro and in cancer cells [103]. Deng et al. have developed a novel strategy for fabricating the sensitive and stable biosensor that was present by layer-by-layer (LBL) self-assembling glucose oxidase (GOD) on multiwall carbon nanotube (CNT) modified glassy carbon (GC) electrode. GOD was immobilized on the negatively charged CNT surface by alternatively assembling a cationic poly(ethylenimine) (PEI) layer and a GOD layer. Therefore, the developed strategy is ideal for the direct electrochemistry of the redox enzymes and the construction of the sensitive and stable enzyme biosensor [104]. Du et al. have proposed a simple method to immobilize acetylcholinesterase (AChE) on polypyrrole (PPy) and polyaniline (PANI) copolymer doped with multiwalled carbon nanotubes (MWCNTs). The synthesized PAn-PPyMWCNTs copolymer presented a porous and homogeneous morphology, which provided an ideal size to entrap enzyme molecules. Due to the biocompatible microenvironment provided by the copolymer network, the obtained composite was devised for AChE attachment, resulting in a stable AChE biosensor for screening of organophosphates (OPs) exposure. MWCNTs promoted electron-transfer reactions at a lower potential and catalyzed the electro-oxidation of thiocholine, thus increasing detection sensitivity. The developed biosensor exhibited good reproducibility and acceptable stability, thus providing a new promising tool for analysis of enzyme inhibitors [105]. Uang and Chou have investigated the $\mathrm{pH}$ effect on the electropolymerization in the presence of glucose oxidase on the characteristics of glucose oxidase/polypyrrole (PPy) biosensor [106]. Borole et al. have constructed glucose biosensors based on electropolymerized polyaniline, poly(o-toluidine) and poly(aniline-cotoluidine), respectively [107]. Seker and Becerik have electrochemically entrapped glucose oxidase into polypyrrole matrix along with $p$-benzoquinone in piperazine ethyl sulphate (PIPES) buffer [108]. It is revealed that application of the artificial network analysis applied to the nonlinear calibration plot can be used to predict the sensor failure detection. Ramanavicius et al. have prepared polypyrrole in the presence of glucose oxidase from Penicillium vitale, glucose, and oxygen 
revealing that optimal conditions of glucose oxidase activity $(\mathrm{pH}$ 6.0) are similar to pyrrole polymerization reaction ( $\mathrm{pH}$ 6.5) indicating possible biomedical applications of this conducting polymer [109]. Pan et al. have reported CNTbased glucose biosensor using immobilization of glucose oxidase in poly ( $o$-aminophenol) and carbon nanotube composite through electrochemical polymerization onto gold electrodes [110]. Curulli et al. have studied the influence of electrolyte nature and its concentration on the kinetics of electropolymerization of monomers such as 1,2and 1,4-diaminobenzene, 2,3- and 1,8-diaminonaphthalene, $o$-anisidine, and on the resulting morphology of nanotubules. Glucose oxidase (GOx), lactate oxidase (LOD), l-aminoacid oxidase (1-AAOD), alcohol oxidase (AOD), glycerol-3-phosphate oxidase (GPO), lysine oxidase (LyOx), and choline oxidase (ChOx) were immobilized on Prussian Blue (PB) layer supported on 1,2-diaminobenzene (1,2$\mathrm{DAB})$ nanotubes onto platinum electrodes [[111]. Callegavi et al. have fabricated the amperometric biosensors for lactate, phenol, catechol, and ethanol by incorporation of their respective enzyme in carbon nanotubes (CNT) matrix [112]. They have shown that the use of CNT electrode yields better results as compared to normal carbon paste electrode. The observed stability of the $\mathrm{H}_{2} \mathrm{O}_{2}$ sensor has attributed to the nano-tubular structure. It has shown that these nanostructured polymers could be utilized for fabrication of enzyme biosensors. Trojanowicz and Miernik have employed avidin-biotin interactions for the immobilization of glucose oxidase on bilayer lipid membrane (BLM) formed on polypyrrole and polyo- phenylenediamine) electrodeposited onto platinum wire, respectively [113]. These BLM-based glucose biosensors resulted in stable and sensitive response with significant reduction from electroactive species such as ascorbic acid, cholesterol, and uric acid, respectively. Myler et al. have reported improved signal linearity of enzyme (glucose oxidase) ultra-microelectrodes fabricated via sonication and deposition of polysiloxane coating onto the working glucose oxidase/polyaniline electrode coated with insulating diaminobenzene [114].

He et al. have developed a sensitive hydrogen peroxide probe based on amplified fluorescence quenching ability of poly (9,9-bis(6-N,N,N-trimethylammonium-hexyl) fluorene phenylene (PFP-NMe ${ }^{3+}$, a cation conjugated polymer) and peroxyfluor-1 borate protective groups. The hydrogen peroxide probe has a detection range of $15-600 \mathrm{nM}$ and can be used for glucose detection. Conducting a polymer-based self-regulating insulin delivery system has recently been reported [115]. Arslan et al. have fabricated a polysiloxane/polypyrrole/tyrosinase electrode by entrapment of tyrosinase in conducting matrix by electrochemical copolymerization for determining phenolic content of green and black tea [116]. Védrine et al. have fabricated an amperometric tyrosinase biosensor based on conducting poly(3,4-ethylenedioxythiophene) (PEDOT) for estimation of herbicides and phenolic compounds [117]. Böyükbayram et al. have made a comparative study of immobilization methods of tyrosinase (Tyr) on electropolymerized conducting and nonconducting polymers for application to the detection of dichlorvos organophosphorus insecticide [118]. Jiang et al. have demonstrated that incorporation of polyvinylalcohol (PVA) onto a polymer film caused higher sensitivity than that of pure PPy sensor [119]. Rahman et al. have fabricated the amperometric biosensor for choline by immobilizing choline oxidase (ChOx) with and without horseradish peroxidase (HRP) onto carboxylated thiophene modified electrodes [120]. They have shown that the electrode with HRP has better performance and these biosensors have the response time of $5 \mathrm{~s}$ and selectivity to interfering species. Kan et al. have reported stronger affinity between uricase and polyaniline prepared by template process resulting in the increased stability of this polyaniline-uricase biosensor [121]. Haccoun et al. have fabricated a reagentless lactate biosensor using electrocopolymerized copolymer film of poly (5-hydroxy-1,4-naphthoquinone-co-5-hydroxy-3-acetic acid-1,4-naphthoquinone) [122]. These studies show that the presence of interferents like acetaminophen, glycine, and ascorbic acid does not influence the response of this mediated (quinine group) copolymer electrode. However, this biosensor can be used for l-lactate estimation upto $1 \mathrm{mM}$ of l-lactate. Bartlett et al. have found that poly(aniline)-poly(anion) composites films can be utilized for electrochemical oxidation of NADHat around $50 \mathrm{mV}$ versus SCE and $\mathrm{pH} 7$ [123]. These results have implications towards the technical development of microelectrodes, biofuel cells, and amperometric biosensors. Asberg and Inganas have cross-linked horseradish peroxidase in highly conducting poly(3,4-ethylene dioxy thiophene) (PEDOT)/(polystyrene sulphonate) (PSS) dispersion using poly-4-vinylpyridine for estimation of hydrogen peroxide [124]. Grennan et al. have reported the horseradish peroxidase immobilized screen-printed electrodes based on chemically polymerized polyaniline/polyvinylsulphonate films, which can be used for the mass production of biosensors [125]. Jia et al. have fabricated horseradish peroxidase (HRP) biosensor by self-assembling gold nanoparticles to a thiol-containing sol-gel network of 3-mercaptaopropyltrimethoxysilane (MPS) [126]. Ngamna et al. have immobilized horseradish peroxidase poly(2methsulphonated polyaniline-5-sulphonic acid)/l-lysine composite [127]. Zhou et al. have observed enhanced peroxidase activity in hemoglobin in sulfonated polyaniline on glassy carbon electrodes [128]. This result has been attributed to the facile interfacial transfer of hemoglobin mediated by sulphonated polyaniline. Lindgren et al. have immobilized horseradish peroxidase (HRP), sweet potato peroxidase (SPP), and peanut peroxidase (PNP) tobacco peroxidase (TOP) on graphite electrodes [129]. The peroxidase electrodes were used for estimation of $\mathrm{H}_{2} \mathrm{O}_{2}$. Dai et al. electrochemically immobilized cytochrome $\mathrm{C}$ on a NaY Zeolite modified electrode [130]. This electrode displayed excellent response to the reduction of $\mathrm{H}_{2} \mathrm{O}_{2}$ without the use of electron mediator and hence could be used for $\mathrm{H}_{2} \mathrm{O}_{2}$ detection. Brahim et al. have developed a $\mathrm{p}(2-$ hydroxyethyl methacrylate/polypyrrole) system containing glucose oxidase, cholesterol oxidase, and galactose oxidase [131]. The observed stability of 9 months for this system indicates that this biosensor can be subcutaneously used 
to monitor glucose, cholesterol, and galactose. Bijanowska et al. have made a comparison of urea estimation in blood plasma and in dialysate for the physiological and the pathological range by enzyme field effect transistor (EnFET) based detection of $\mathrm{pH}$ and $\mathrm{pNH}_{4}$ [132]. It is concluded that $\mathrm{pNH}_{4}$-based biosensors require predilution whereas for $\mathrm{pH}$ biosensors both for blood plasma and dialysate do not require dilution. Zhang et al. have discovered that stable mixed amphiphile (octadecylamine, ODA/behenic acid, BA)/urease Langmuir-Blodgett films can be formed onto the hydrolyzed surface of a pH-ISFET [133]. Rebriiev and Starodub have fabricated a urea biosensor based on ion-sensitive-field-effect transistor (ISFET) and photopolymeric membrane obtained by irradiation of a liquid mixture comprising vinyl pyrrolidone, oligo urethane methacrylate, and oligocarbonate methacrylate. This urea biosensor exhibited high sensitivity, response time [134]. Pinto and Schanze have demonstrated the application of conjugated polyelectrolytes (CPEs) based on pendent ionic sulphonate and carboxylate groups for estimation of protease activity. The sensor has been used for estimation of low enzyme concentrations and enzyme-catalyzed kinetics. This technique can be used to develop assays for kinases, phosphates, lipases and esterases, and so forth [135]. Ivanov et al. have used glassy carbon electrodes modified with polyaniline for the immobilization of cholinesterase using cross-linking technique [136] for the estimation of pesticides (trichlorfon, coumaphos, methiocarb, and aldicarb). Rahman et al. have covalently immobilized pyruvate oxidase onto nanoparticles comprising of poly-5, 2:5, 2-terthiophene-3-craboxylic acid, poly-TTCA (nano-CP) on a glassy electrode for amperometric detection of phosphate ions [137]. Qu et al. have reported an amperometric biosensor for detection of choline based on polyaniline multilayer film and layer-by-layer assembled functionalized carbon nanotube [138]. Biloivan et al. demonstrated that protein selective microelectrodes can be fabricated by immobilization of different proteinases such as trypsin, pronase E, and carboxypeptidase B on surface of platinum electrodes modified by conducting PPy $[3,3-\mathrm{Co}(1,2-$ C2B9H11) $]_{2}$ [139]. Lee and Cui have presented low-cost, transparent, and flexible ion-sensitive field-effect transistors (ISFETs) as $\mathrm{pH}$ and glucose sensors. Single-walled carbon nanotubes (SWCNTs) and poly(diallyldimethylammonium chloride, PDDA) are deposited by layer-by-layer (LbL) self-assembly between two metallic electrodes patterned on a polyethylene terephthalate substrate. The LbL self-assembly of nanomaterials and enzymes on the transparent and flexible substrate suggests various chemical and biological sensors suitable for in vivo application [140]. Tan et al. have reported the facile preparation of polymer-enzymemultiwalled carbon nanotubes (MWCNTs) cast films accompanying in situ laccase (Lac) catalyzed polymerization for electrochemical biosensing and biofuel cell applications. The proposed biomacromolecule-immobilization platform based on enzyme-catalyzed polymerization may be useful for preparing many other multifunctional polymeric bionanocomposites for wide applications [141]. Xiao et al. have designed polymerized ionic liquid-wrapped carbon nanotubes (PIL-CNTs) for the first time for direct electrochemistry and biosensing of redox proteins. The proposed biosensor (GOD/PIL-CNTs/GC electrode) displayed good analytical performance for glucose [142]. Haddad et al. have functionalized single-walled carbon nanotubes with biotin using either electropolymerization or formation of pi-stacking interactions for the construction of biosensors. A biotinylated glucose oxidase as a biomolecule model was immobilized on the biotinylated nanotubes [143]. Xie et al. have developed a novel general methodology for protein immobilization and third-generation biosensor, which involves $\mathrm{Al}^{3+}$ directed polyacrylamide (PAM) self-assembly into an ordered dendriform structure, easily immobilizing enzymes and nanoparticles. The $\mathrm{Al}^{3+}$ directed HRP/PAM/Pt/SWCNT film was one of ideal candidate materials for direct electrochemistry of redox proteins and find potential applications in biomedical, food, and environmental analysis [144]. Min and Yoo have developed a novel 3-dimensional single-wall carbon nanotube (SWNTs) polypyrrole (Ppy) composite as an electrode by chemically polymerizing polypyrrole onto SWNTs using a $\mathrm{LiClO}_{4}$ oxidant. This tyrosinase SWNTPpy composite electrode was used for amperometric detection of dopamine in the presence of ascorbic acid [145]. Bhambi et al. have constructed a highly sensitive, amperometric uric acid biosensor based on PANI-carbon nanotubes for determination of uric acid level in serum [146]. Barik et al. have immobilized cholesterol oxidase ( $\mathrm{ChOx}$ ) covalently onto polyaniline-carboxymethyl cellulose (PANI-CMC) nanocomposite film onto indium tin oxide (ITO) coated glass plate using glutaraldehyde as a cross-linker for the detection of cholesterol [147]. Dhand et al. have fabricated ChOx/Glu/PANI-NT/ITO bioelectrode via electrophoretic technique using glutaraldehyde (Glu) as cross-linker for the cholesterol detection [148]. Dhand et al. have also prepared polyaniline nanospheres (PANI-NS) via morphological transformation of micelle polymerized camphorsulfonic acid doped polyaniline nanotubes in the presence of ethylene glycol and a PANI-NS (60$80 \mathrm{~nm}$ ) film deposited onto an indium tin oxide (ITO) coated glass plate by coupling chemistry as a cholesterol biosensor [149]. Ansari et al. have fabricated hydrogen peroxide $\left(\mathrm{H}_{2} \mathrm{O}_{2}\right)$ sensor via immobilizing horseradish peroxidase (HRP) onto polyaniline (PANI) cerium oxide $\left(\mathrm{CeO}_{2}\right)$ nano-composite film onto indium tin oxide (ITO) coated glass substrate using electrochemical technique [150]. Dhand et al. have reported nanocomposite film composed of polyaniline (PANI) and multiwalled carbon nanotubes (MWCNT), electrophoretically onto indium tin oxide (ITO) coated glass plate, used for covalent immobilization of cholesterol oxidase (ChOx) via $\mathrm{N}$ ethyl- $\mathrm{N}^{\prime}$-(3-dimethylaminopropyl) carbodiimide (EDC) and N-hydroxysuccinimide (NHS) chemistry [151]. Pandey et al. have fabricated gold nanoparticles (AuNPs) via self-assembled onto electrochemically deposited polyaniline (PANI) films on indium tin oxide (ITO) coated glass plates, covalently immobilized glucose oxidase $(\mathrm{GOx})$ in the near vicinity of gold nanoparticles sing $\mathrm{N}$-ethyl- $\mathrm{N}^{\prime}$-(3-dimethylaminopropyl) carbodiimide 
(EDC)/N-hydroxysuccinimide (NHS), chemistry between amino groups of PANI and $\mathrm{COOH}$ groups of GOx for the detection of glucose [152]. Matharu et al. have reported cholesterol oxidase (ChOx) linked Langmuir-Blodgett (LB) monolayers of polyaniline- (PANI-) stearic acid (SA) onto indium tin oxide (ITO) coated glass plates via glutaraldehyde (Glu) chemistry for cholesterol estimation [153]. Dhand et al. fabricated cholesterol oxidase (ChOx) via being covalently immobilized onto electrophoretically deposited conducting polymer film (on indium tin oxide (ITO) glass plate derived from nanostructured polyaniline (PANI) colloidal suspension using $\mathrm{N}$-ethyl- $\mathrm{N}^{\prime}$-(3-dimethylaminopropyl) carbodiimide (EDC) and N-hydroxysuccinimide (NHS) chemistry [154]. Singh et al. have reported covalently immobilized cholesterol esterase (ChEt) and cholesterol oxidase $(\mathrm{ChOx})$ on electrochemically prepared polyaniline (PANI) films [155]. Arora et al. have reported uricase immobilized using glutaraldehyde as cross-linker onto electrochemically synthesized polyaniline (PANI) films used to measure uric acid concentration in serum [156]. Sharma et al. developed an amperometric lactose biosensor by immobilizing lactase (EC 3.2.1.23) and galactose oxidase $(\mathrm{GaO})$ (EC 1.1.3.9) in Langmuir-Blodgett (LB) films of poly(3-hexyl thiophene) (P3HT)/stearic acid (SA) for estimation of lactose in milk and its products to prevent "lactose intolerance." The reusability of electrode was found ten times with 3\% loss in current response. The working electrode may be used for the estimation of lactose/galactose in food and biological fluids [157]. Sharma et al. have reported an amperometric biosensor to estimate galactose in human blood serum using monolayers of poly(3-hexyl thiophene) and galactose oxidase/stearic acid in chloroform and dispensed on to the air-water interface of LangmuirBlodgett trough. The amperometric galactose biosensor was thus fabricated [158]. Singhal et al. have reported Langmuir-Blodgett films of poly(3-hexyl thiophene) prepared by simultaneous entrapment of glucose oxidase and transferred onto the indium tin oxide-coated glass plates [159]. Chaubey et al. have reported the electrochemical entrapment of polyaniline (PANI) onto sol-gel derived tetraethylorthosilicate (TEOS) films deposited onto indium tin oxide (ITO) coated glass utilized for immobilization of lactate dehydrogenase $(\mathrm{LDH})$ for the lactate measurement [160]. Arya et al. obtained $\mathrm{ChOx} / \mathrm{FANB} / \mathrm{ODT} / \mathrm{Au}$ selfassembled monolayer based bioelectrode to estimate cholesterol by surface plasmon resonance technique [161].

\section{Conclusions}

The electroactive property of organic conducting polymers makes them good candidates for highly selective, specific, stable, economic, and handy biosensing devices, which are widely used in biosensor industries. The growing need for rapid development of analytical devices requiring smaller sample volumes, decreased power consumption, and improved performance. So that the urgent need for reduction of shape and size dimensions of nanomaterials display unique properties like increased surface area and enhanced electrical/optical properties, which make them suitable for numerous applications such as nanoelectronics, photovoltaics and chemical/biological sensing. In this review nanomaterials were incorporated in biosensor devices, it is possible to achieve enhanced sensitivity, improved response time, and smaller size. The nanomaterials geometries are particularly relevant, and specifically focus the increasing importance of inorganic, organic nanostructures, conducting polymer nanostructures with carbon nanotubes towards the development of various kinds of biosensors. The focus of this review is an in-depth analysis of the recent achievements in the concern field and the major challenges that are to be overcome for the widespread use of applications such as point-of-care diagnostics, food safety/control, and environmental monitoring.

\section{Acknowledgments}

R. P. Singh is thankful to Professor A. C. Pandey, coordinator of Nanotechnology Application Centre, University of Allahabad, and also financial support of Nano-Mission (SR/NM/NS-87/2008), Department of Science and Technology, Government of India and Department of Atomic Energy, Board of Research in Nuclear Sciences (DAE-BRNS), Government of India, Sanction no. 2010/34/37/BRNS with ATC.

\section{References}

[1] D. Liu, K. Ge, K. Chen, L. Nie, and S. Yao, "Clinical analysis of urea in human blood by coupling a surface acoustic wave sensor with urease extracted from pumpkin seeds," Analytica Chimica Acta, vol. 307, no. 1, pp. 61-69, 1995.

[2] M. Mascini, "Enzyme-based optical-fibre biosensors," Sensors and Actuators B, vol. 29, no. 1-3, pp. 121-125, 1995.

[3] X. Xie, A. A. Suleiman, and G. G. Guilbault, "Determination of urea in serum by a fiber-optic fluorescence biosensor," Talanta, vol. 38, no. 10, pp. 1197-1200, 1991.

[4] S. B. Adeloju, S. J. Shaw, and G. G. Wallace, "Polypyrrolebased potentiometric biosensor for urea: part 1. Incorporation of urease," Analytica Chimica Acta, vol. 281, no. 3, pp. 611-620, 1993.

[5] S. B. Adeloju, S. J. Shaw, and G. G. Wallace, "Polypyrrolebased potentiometric biosensor for urea: part 2. Analytical optimisation," Analytica Chimica Acta, vol. 281, no. 3, pp. 621-627, 1993.

[6] M. F. Esteve and S. Alegret, "The modern student laboratory: a practical approach to chemical sensors through potentiometric transducers: determination of urea in serum by means of a biosensor," Journal of Chemical Education, vol. 71, no. 3, pp. A67-A70, 1994.

[7] D. Liu, M. E. Meyerhoff, H. D. Goldberg, and R. B. Brown, "Potentiometric ion- and bioselective electrodes based on asymmetric polyurethane membranes," Analytica Chimica Acta, vol. 274, no. 1, pp. 37-46, 1993.

[8] K. Chen, D. Liu, L. Nie, and S. Yao, "Determination of urea in urine using a conductivity cell with surface acoustic wave resonator-based measurement circuit," Talanta, vol. 41, no. 12, pp. 2195-2200, 1994. 
[9] A. S. Jdanova, S. Poyard, A. P. Soldatkin, N. JaffrezicRenault, and C. Martelet, "Conductometric urea sensor: use of additional membranes for the improvement of its analytical characteristics," Analytica Chimica Acta, vol. 321, no. 1, pp. 35-40, 1996.

[10] R. P. Singh, Y. J. Kim, B. K. Oh, and J. W. Choi, "Glutathiones-transferase based electrochemical biosensor for the detection of captan," Electrochemistry Communications, vol. 11, pp. 181-185, 2009.

[11] R. E. Adams, "Coulometric flow analyzer for use with immobilized enzyme reactors," Analytical Chemistry, vol. 50, no. 7, pp. 944-950, 1978.

[12] S. B. Adeloju, S. J. Shaw, and G. G. Wallace, "Polypyrrolebased amperometric flow injection biosensor for urea," Analytica Chimica Acta, vol. 323, no. 1-3, pp. 107-113, 1996.

[13] W. O. Ho, S. Krause, C. J. McNeil et al., "Electrochemical sensor for measurement of urea and creatinine in serum based on ac impedance measurement of enzyme-catalyzed polymer transformation," Analytical Chemistry, vol. 71, no. 10, pp. 1940-1946, 1999.

[14] R. P. Singh, B. K. Oh, K. K. Koo, J. Y. Jyoung, S. Jeong, and J. W. Choi, "Biosensor arrays for environmental pollutants detection," Biochip Journal, vol. 2, no. 4, pp. 223-234, 2009.

[15] R. P. Singh, D. Y. Kang, B. K. Oh, and J. W. Choi, "Polyaniline based catalase biosensor for the detection of hydrogen peroxide and azide," Biotechnology and Bioprocess Engineering, vol. 14, no. 4, pp. 443-449, 2009.

[16] D. R. Thevenot, K. Toth, R. A. Durst, and G. S. Wilson, "Electrochemical biosensors: recommended definitions and classification," Pure and Applied Chemistry, vol. 71, pp. 23332348, 1999.

[17] R. P. Singh, B. K. Oh, and J. W. Choi, "Application of peptide nucleic acid towards development of nanobiosensor arrays," Bioelectrochemistry, vol. 79, no. 2, pp. 153-161, 2010.

[18] R. P. Singh, D. Y. Kang, and J. W. Choi, "Nanofabrication of bio-self assembled monolayer and its electrochemical property for toxicant detection," Journal of Nanoscience and Nanotechnology, vol. 11, no. 1, pp. 408-412, 2011.

[19] L. C. Clark and C. Lyons, "Electrode systems for continuous monitoring in cardiovascular surgery," Annals of the New York Academy of Sciences, vol. 102, pp. 29-45, 1962.

[20] L. Murphy, "Biosensors and bioelectrochemistry," Current Opinion in Chemical Biology, vol. 10, no. 2, pp. 177-184, 2006.

[21] M. Hartmann, "Ordered mesoporous materials for bioadsorption and biocatalysis," Chemistry of Materials, vol. 17, no. 18, pp. 4577-4593, 2005.

[22] D. M. Ivory, G. G. Miller, J. M. Sowa, L. W. Shacklette, R. R. Chance, and R. H. Baughman, "Highly conducting chargetransfer complexes of poly(p-phenylene)," The Journal of Chemical Physics, vol. 71, no. 3, pp. 1506-1507, 1979.

[23] H. H. Weetall, A. Druzhko, A. R. de Lera, R. Alvarez, and B. Robertson, "Measurement of proton release and uptake by analogs of bacteriorhodopsin," Bioelectrochemistry and Bioenergetics, vol. 51, no. 1, pp. 27-33, 2000.

[24] B. Zinger and L. L. Miller, "Timed release of chemicals from polypyrrole films," Journal of the American Chemical Society, vol. 106, no. 22, pp. 6861-6863, 1984.

[25] N. Gupta, S. Sharma, I. A. Mir, and D. Kumar, "Advances in sensors based on conducting polymers," Journal of Scientific and Industrial Research, vol. 65, no. 7, pp. 549-557, 2006.

[26] B. Adhikari and S. Majumdar, "Polymer in sensor applications," Progress in Polymer Science, vol. 29, no. 7, pp. 699-766, 2004.
[27] J. Tschmelak, G. Proll, J. Riedt et al., "Automated Water Analyser Computer Supported System (AWACSS) part I: project objectives, basic technology, immunoassay development, software design and networking," Biosensors and Bioelectronics, vol. 20, no. 8, pp. 1499-1508, 2005.

[28] M. Gerard, A. Chaubey, and B. D. Malhotra, "Application of conducting polymers to biosensors," Biosensors and Bioelectronics, vol. 17, no. 5, pp. 345-359, 2002.

[29] S. M. Park, "Electrochemistry of p-conjugated polymers," in Handbook of Organic Conductive Molecules and Polymers, $\mathrm{H}$. S. Nalwa, Ed., vol. 3, pp. 429-469, Wiley, Chichester, UK, 1997.

[30] P. N. Bartlett and J. M. Cooper, "A review of the immobilized enzymes in electropolymerized films," Journal of Electroanalytical Chemistry, vol. 362, no. 1-2, pp. 1-12, 1993.

[31] W. Li, H. Zhao, and G. G. Wallace, "Pulsed electrochemical detection of proteins using conducting polymer sensors," Analytica Chimica Acta, vol. 315, no. 1-2, pp. 27-32, 1995.

[32] D. S. Park, Y. B. Shim, and S. M. Park, "Degradation of electrochemically prepared polypyrrole in aqueous sulfuric acid," Journal of The Electrochemical Society, vol. 140, no. 3, pp. 609-614, 1993.

[33] P. Blanchard, P. Leriche, P. Frere, and J. Roncali, "Advanced functional polythiophene based on tailored precursors," in Handbook of Conducting Polymers, Conjugated polymers, T. A. Skotheim and J. R. Reynolds, Eds., chapter 13, pp. 1-77, CRC Press, Bocaraton, Fla, USA, 3rd edition, 2006.

[34] R. P. Singh and J. W. Choi, "Biosensors development based on potential target of conducting polymers," Sensors \& Transducers Journal, vol. 104, no. 5, pp. 1-18, 2009.

[35] M. Jeffries-El and D. Mccullough, "Regioregular polythiophene," in Handbook of Conducting Polymers, Conjugated Polymers, T. A. Skotheim and J. R. Reynolds, Eds., chapter 9, pp. 1-49, CRC Press, Bocaraton, Fla, USA, 3rd edition, 2006.

[36] J. W. Lee, D. S. Park, Y. B. Shim, and S. M. Park, "Electrochemical characterization of poly(1,8-diaminonaphthalene): a functionalized polymer," Journal of the Electrochemical Society, vol. 139, no. 12, pp. 3507-3514, 1992.

[37] E. W. Paul, A. J. Ricco, and M. S. Wrighton, "Resistance of polyaniline films as a function of electrochemical potential and the fabrication of polyaniline-based microelectronic devices," Journal of Physical Chemistry, vol. 89, no. 8, pp. 1441-1447, 1985.

[38] A. Mulchandani and C. L. Wang, "Bienzyme sensors based on poly(anilinomethylferrocene)-modified electrodes," Electroanalysis, vol. 8, no. 5, pp. 414-419, 1996.

[39] P. N. Bartlett and R. G. Whitaker, "Strategies for the development of amperometric enzyme electrodes," Biosensors, vol. 3, no. 6, pp. 359-379, 1987.

[40] A. Ramanaviciene and A. Ramanavicius, Advanced Biomaterials for Medical Applications, Kluwer Academic Publishers, Dodrecht, The Netherlands, 2004.

[41] A. Malinauskas, J. Malinauskiene, and A. Ramanavičius, "Conducting polymer-based nanostructurized materials: electrochemical aspects," Nanotechnology, vol. 16, no. 10, pp. R51-R62, 2005.

[42] W. Schuhmann, R. Lammert, B. Uhe, and H. L. Schmidt, "Polypyrrole, a new possibility for covalent binding of oxidoreductases to electrode surfaces as a base for stable biosensors," Sensors and Actuators B, vol. 1, no. 1-6, pp. 537541, 1990.

[43] L. Gorton, A. Lindgren, T. Larsson, F. D. Munteanu, T. Ruzgas, and I. Gazaryan, "Direct electron transfer between heme-containing enzymes and electrodes as basis for third 
generation biosensors," Analytica Chimica Acta, vol. 400, no. 1-3, pp. 91-108, 1999.

[44] W. Schuhmann, "Amperometric enzyme biosensors based on optimised electron-transfer pathways and non-manual immobilisation procedures," Reviews in Molecular Biotechnology, vol. 82, no. 4, pp. 425-441, 2002.

[45] T. Ramanathan, F. T. Fisher, R. S. Ruoff, and L. C. Brinson, "Amino-fimctionalized carbon nanotubes for binding to polymers and biological systems," Chemistry of Materials, vol. 17, no. 6, pp. 1290-1295, 2005.

[46] S. Carrara, V. Bavastrello, D. Ricci, E. Stura, and C. Nicolini, "Improved nanocomposite materials for biosensor applications investigated by electrochemical impedance spectroscopy," Sensors and Actuators B, vol. 109, no. 2, pp. 221226, 2005.

[47] J. I. Anzai, T. Hoshi, and T. Osa, "Avidin-biotin complexation for enzyme sensor applications," Trends in Analytical Chemistry, vol. 13, no. 5, pp. 205-210, 1994.

[48] L. Nobs, F. Buchegger, R. Gurny, and E. Allémann, "Poly(lactic acid) nanoparticles labeled with biologically active Neutravidin for active targeting," European Journal of Pharmaceutics and Biopharmaceutics, vol. 58, no. 3, pp. 483490, 2004.

[49] R. Gref, P. Couvreur, G. Barratt, and E. Mysiakine, "Surfaceengineered nanoparticles for multiple ligand coupling," Biomaterials, vol. 24, no. 24, pp. 4529-4537, 2003.

[50] B. D. Malhotra and A. Chaubey, "Biosensors for clinical diagnostics industry," Sensors and Actuators B, vol. 91, no. 13, pp. 117-127, 2003.

[51] R. A. Doong, H. M. Shih, and S. H. Lee, "Sol-gel-derived array DNA biosensor for the detection of polycyclic aromatic hydrocarbons in water and biological samples," Sensors and Actuators B, vol. 111-112, pp. 323-330, 2005.

[52] S. Tombelli, M. Mascini, C. Sacco, and A. P. F. Turner, "A DNA piezoelectric biosensor assay coupled with a polymerase chain reaction for bacterial toxicity determination in environmental samples," Analytica Chimica Acta, vol. 418, no. 1, pp. 1-9, 2000.

[53] T. Roopa, N. Kumar, S. Bhattacharya, and G. V. Shivashankar, "Dynamics of membrane nanotubulation and DNA selfassembly," Biophysical Journal, vol. 87, no. 2, pp. 974-979, 2004.

[54] J. H. Ng and L. L. Ilag, "Biomedical applications of protein chips," Journal of Cellular and Molecular Medicine, vol. 6, no. 3, pp. 329-340, 2002.

[55] S. L. Beaucage, "Strategies in the preparation of DNA oligonucleotide arrays for diagnostic applications," Current Medicinal Chemistry, vol. 8, no. 10, pp. 1213-1244, 2001.

[56] J. Wang, "Nanomaterial-based electrochemical biosensors," The Analyst, vol. 130, no. 4, pp. 421-426, 2005.

[57] J. Q. Brown and M. J. McShane, "Modeling of spherical fluorescent glucose microsensor systems: design of enzymatic smart tattoos," Biosensors and Bioelectronics, vol. 21, no. 9, pp. 1760-1769, 2006.

[58] A. Wolter, P. Rannou, J. P. Travers, B. Gilles, and D. Djurado, "Model for aging in $\mathrm{HCl}$-protonated polyaniline: structure, conductivity, and composition studies," Physical Review B, vol. 58, no. 12, pp. 7637-7647, 1998.

[59] M. S. Rahmanifar, M. F. Mousavi, M. Shamsipur, and S. Riahi, "A study on the influence of anionic surfactants on electrochemical degradation of polyaniline," Polymer Degradation and Stability, vol. 91, no. 12, pp. 3463-3468, 2006.
[60] N. Chandrakanthi and M. A. Careem, "Thermal stability of polyaniline," Polymer Bulletin, vol. 44, no. 1, pp. 101-108, 2000.

[61] T. A. Sergeyeva, N. V. Lavrik, S. A. Piletsky, A. E. Rachkov, and A. V. El'skaya, "Polyaniline label-based conductometric sensor for IgG detection," Sensors and Actuators B, vol. 34, no. 1-3, pp. 283-288, 1996.

[62] Y. C. Luo and J. S. Do, "Urea biosensor based on PANi(urease)-Nafion/Au composite electrode," Biosensors and Bioelectronics, vol. 20, no. 1, pp. 15-23, 2004.

[63] Y. Iribe and M. Suzuki, Proceedings of the Seventh World Congress on Biosensors, Elsevier, Osaka, Japan, 2002.

[64] H. Ding, M. Wan, and Y. Wei, "Controlling the diameter of polyaniline nanofibers by adjusting the oxidant redox potential," Advanced Materials, vol. 19, no. 3, pp. 465-469, 2007.

[65] E. S. Forzani, H. Zhang, L. A. Nagahara, I. Amlani, R. Tsui, and N. Tao, "A conducting polymer nanojunction sensor for glucose detection," Nano Letters, vol. 4, no. 9, pp. 1785-1788, 2004.

[66] B. Sreedhar, P. Radhika, B. Neelima, N. Hebalkar, and M. V. B. Rao, "Synthesis and characterization of polyaniline: nanospheres, nanorods, and nanotubes-catalytic application for sulfoxidation reactions," Polymers for Advanced Technologies, vol. 20, no. 12, pp. 950-958, 2009.

[67] N. G. R. Mathebe, A. Morrin, and E. I. Iwuoha, "Electrochemistry and scanning electron microscopy of polyaniline/peroxidase-based biosensor," Talanta, vol. 64, no. 1, pp. 115-120, 2004.

[68] I. Michira, R. Akinyeye, V. Somerset et al., "Synthesis, characterisation of novel polyaniline nanomaterials and application in amperometric biosensors," Macromolecular Symposia, vol. 255, pp. 57-69, 2007.

[69] P. Wang, S. Li, and J. Kan, "A hydrogen peroxide biosensor based on polyaniline/FTO," Sensors and Actuators B, vol. 137, no. 2, pp. 662-668, 2009.

[70] E. I. Iwuoha, D. S. De Villaverde, N. P. Garcia, M. R. Smyth, and J. M. Pingarron, "Reactivities of organic phase biosensors. 2. The amperometric behaviour of horseradish peroxidase immobilised on a platinum electrode modified with an electrosynthetic polyaniline film," Biosensors and Bioelectronics, vol. 12, no. 8, pp. 749-761, 1997.

[71] G. Kathleen, A. J. Killard, C. J. Hanson, A. A. Cafolla, and M. R. Smyth, "Optimisation and characterisation of biosensors based on polyaniline," Talanta, vol. 68, no. 5, pp. 1591-1600, 2006.

[72] M. E. G. Lyons, C. H. Lyons, C. Fitzgerald, and T. Bannon, "Poly(pyrrole) based amperometric sensors: theory and characterization," The Analyst, vol. 4, no. 118, pp. 361-369, 1993.

[73] S. Mu and H. Xue, "Bioelectrochemical characteristics of glucose oxidase immobilized in a polyaniline film," Sensors and Actuators B, vol. 31, no. 3, pp. 155-160, 1996.

[74] A. Morrin, O. Ngamna, A. J. Killard, S. E. Moulton, M. R. Smyth, and G. G. Wallace, "An amperometric enzyme biosensor fabricated from polyailine nanoparticles," Electroanalysis, vol. 17, no. 5-6, pp. 423-430, 2005.

[75] X. Luo, A. Morrin, A. J. Killard, and M. R. Smyth, "Application of nanoparticles in electrochemical sensors and biosensors," Electroanalysis, vol. 18, no. 4, pp. 319-326, 2006.

[76] Z. Wang, S. Liu, P. Wu, and C. Cai, "Detection of glucose based on direct electron transfer reaction of glucose oxidase immobilized on highly ordered polyaniline nanotubes," Analytical Chemistry, vol. 81, no. 4, pp. 1638-1645, 2009. 
[77] L. Xu, Y. Zhu, L. Tang, X. Yang, and C. Li, "Dendrimerencapsulated Pt nanoparticles/polyaniline nanofibers for glucose detection," Journal of Applied Polymer Science, vol. 109, no. 3, pp. 1802-1807, 2008.

[78] Y. Xian, Y. Hu, F. Liu, Y. Xian, H. Wang, and L. Jin, "Glucose biosensor based on Au nanoparticles-conductive polyaniline nanocomposite," Biosensors and Bioelectronics, vol. 21, no. 10, pp. 1996-2000, 2006.

[79] H. Zhou, H. Chen, S. Luo, J. Chen, W. Wei, and Y. Kuang, "Glucose biosensor based on platinum microparticles dispersed in nano-fibrous polyaniline," Biosensors and Bioelectronics, vol. 20, no. 7, pp. 1305-1311, 2005.

[80] K. Ramanathan, M. K. Ram, B. D. Malhotra, and A. S. N. Murthy, "Application of polyaniline-Langmuir-Blodgett films as a glucose biosensor," Materials Science and Engineering C, vol. 3, no. 3-4, pp. 159-163, 1995.

[81] L. R. Nemzer, A. Schwartz, and A. J. Epstein, "Enzyme entrapment in reprecipitated polyaniline nano- and microparticles," Macromolecules, vol. 43, no. 9, pp. 43244330, 2010.

[82] D. D. Borole, U. R. Kapadi, P. P. Mahulikar, and D. G. Hundiwale, "Glucose oxidase electrodes of poly(o-anisidine), poly(o-toluidine), and their copolymer as biosensors: a comparative study," Journal of Applied Polymer Science, vol. 94, no. 5, pp. 1877-1884, 2004.

[83] H. Xue, Z. Shen, and C. Li, "Improved selectivity and stability of glucose biosensor based on in situ electropolymerized polyaniline-polyacrylonitrile composite film," Biosensors and Bioelectronics, vol. 20, no. 11, pp. 2330-2334, 2005.

[84] L. Shi, Y. Xiao, and I. Willner, "Electrical contacting of glucose oxidase by DNA-templated polyaniline wires on surfaces," Electrochemistry Communications, vol. 6, no. 10, pp. 1057-1060, 2004.

[85] M. Zhao, X. Wu, and C. Cai, "Polyaniline nanofibers: synthesis, characterization, and application to direct electron transfer of glucose oxidase," Journal of Physical Chemistry C, vol. 113, no. 12, pp. 4987-4996, 2009.

[86] S. Sukeerthi and A. Q. Contractor, "A study of polyaniline microtubules: toward superior transducing abilities," Chemistry of Materials, vol. 10, no. 9, pp. 2412-2418, 1998.

[87] A. Q. Contractor, R. S. Srinivasa, S. Kumar, R. Narayanan, S. Sukeerthi, and R. Lal, "Conducting polymer-based biosensors," Electrochimica Acta, vol. 39, no. 8-9, pp. 1321-1324, 1994.

[88] H. Sangodkar, S. Sukeerthi, R. Lal, R. S. Srinivasa, and A. Q. Contractor, "A biosensorarray based on polyaniline," Analytical Chemistry, vol. 68, no. 5, pp. 779-783, 1996.

[89] A. A. Karyakin, M. Vuki, L. V. Lukachova et al., "Processible polyaniline as an advanced potentiometric $\mathrm{pH}$ transducer: application to biosensors," Analytical Chemistry, vol. 71, no. 13, pp. 2534-2540, 1999.

[90] P. D. Gaikwad, D. J. Shirale, V. K. Gade et al., "Immobilization of GOD on electrochemically synthesized PANI film by crosslinking via glutaraldehyde for determination of glucose," International Journal of Electrochemical Science, vol. 1, pp. 425-434, 2006.

[91] H. Wang and S. Mu, "Bioelectrochemical characteristics of cholesterol oxidase immobilized in a polyaniline film," Sensors and Actuators B, vol. 56, no. 1, pp. 22-30, 1999.

[92] G. Bayramoğlu, M. Karakısla, B. Altıntasla, A. U. Metin, M. Saçak, and M. Y. Arıca, "Polyaniline grafted polyacylonitrile conductive composite fibers for reversible immobilization of enzymes: stability and catalytic properties of invertase," Process Biochemistry, vol. 44, no. 8, pp. 880-885, 2009.
[93] Y. D. Kim and S. Jeon, "Amperometric superoxide microbiosensor based on polyaniline-superoxide dismutase modified electrode," Analytical Sciences, vol. 17, pp. a97-a99, 2001.

[94] D. Shan, Q. Shi, D. Zhu, and H. Xue, "Inhibitive detection of benzoic acid using a novel phenols biosensor based on polyaniline-polyacrylonitrile composite matrix," Talanta, vol. 72, no. 5, pp. 1767-1772, 2007.

[95] L. Castelletti, S. A. Piletsky, A. P. F. Turner, P. G. Righetti, and A. Bossi, "Development of an integrated capillary electrophoresis/sensor for L-ascorbic acid detection," Electrophoresis, vol. 23, no. 2, pp. 209-214, 2002.

[96] J. J. Langer, M. Filipiak, J. Kęcińska, J. Jasnowska, J. Włodarczak, and B. Buładowski, "Polyaniline biosensor for choline determination," Surface Science, vol. 573, no. 1, pp. 140-145, 2004.

[97] P. N. Bartlett, P. R. Birkin, and E. N. K. Wallace, "Oxidation of $\beta$-nicotinamide adenine dinucleotide (NADH) at poly(aniline)-coated electrodes," Journal of the Chemical Society-Faraday Transactions, vol. 93, no. 10, pp. 19511960, 1997.

[98] F. Tian, B. Xu, L. Zhu, and G. Zhu, "Hydrogen peroxide biosensor with enzyme entrapped within electrodeposited polypyrrole based on mediated sol-gel derived composite carbon electrode," Analytica Chimica Acta, vol. 443, no. 1, pp. 9-16, 2001.

[99] S. Yadav, R. Devi, S. Kumari, S. Yadav, and C. S. Pundir, "An amperometric oxalate biosensor based on sorghum oxalate oxidase bound carboxylated multiwalled carbon nanotubespolyaniline composite film," Journal of Biotechnology, vol. 151, no. 2, pp. 212-217, 2011.

[100] N. Tang, J. Zheng, Q. Sheng, H. Zhang, and R. Liu, "A novel $\mathrm{H}_{2} \mathrm{O}_{2}$ sensor based on the enzymatically induced deposition of polyaniline at a horseradish peroxide/aligned single-wall carbon nanotubes modified Au electrode," The Analyst, vol. 136, no. 4, pp. 781-786, 2011.

[101] D. Chen, C. Chen, and D. Du, "Detection of organophosphate pesticide using polyaniline and carbon nanotubes composite based on acetylcholinesterase inhibition," Journal of Nanoscience and Nanotechnology, vol. 10, no. 9, pp. 56625666, 2010.

[102] P. Vatsyayan, S. Bordoloi, and P. Goswami, "Large catalase based bioelectrode for biosensor application," Biophysical Chemistry, vol. 153, no. 1, pp. 36-42, 2010.

[103] S. Rajesh, A. K. Kanugula, K. Bhargava, G. Ilavazhagan, S. Kotamraju, and C. Karunakaran, "Simultaneous electrochemical determination of superoxide anion radical and nitrite using $\mathrm{Cu}$, ZnSOD immobilized on carbon nanotube in polypyrrole matrix," Biosensors and Bioelectronics, vol. 26, no. 2, pp. 689-695, 2010.

[104] C. Deng, J. Chen, Z. Nie, and S. Si, "A sensitive and stable biosensor based on the direct electrochemistry of glucose oxidase assembled layer-by-layer at the multiwall carbon nanotube-modified electrode," Biosensors and Bioelectronics, vol. 26, no. 1, pp. 213-219, 2010.

[105] D. Du, X. Ye, J. Cai, J. Liu, and A. Zhang, "Acetylcholinesterase biosensor design based on carbon nanotubeencapsulated polypyrrole and polyaniline copolymer for amperometric detection of organophosphates," Biosensors and Bioelectronics, vol. 25, no. 11, pp. 2503-2508, 2010.

[106] Y. M. Uang and T. C. Chou, "Fabrication of glucose oxidase/polypyrrole biosensor by galvanostatic method in various $\mathrm{pH}$ aqueous solutions," Biosensors and Bioelectronics, vol. 19, no. 3, pp. 141-147, 2003. 
[107] D. D. Borole, U. R. Kapadi, P. P. Mahulikar, and D. G. Hundiwale, "Glucose oxidase electrodes of polyaniline, poly(o-toluidine) and their copolymer as a biosensor: a comparative study," Polymers for Advanced Technologies, vol. 15, no. 6, pp. 306-312, 2004.

[108] S. Seker and I. Becerik, "A neural network model in the calibration of glucose sensor based on the immobilization of glucose oxidase into polypyrrole matrix," Electroanalysis, vol. 16, no. 18, pp. 1542-1549, 2004.

[109] A. Ramanavicius, A. Kausaite, A. Ramanaviciene, J. Acaite, and A. Malinauskas, "Redox enzyme-glucose oxidaseinitiated synthesis of polypyrrole," Synthetic Metals, vol. 156, no. 5-6, pp. 409-413, 2006.

[110] D. Pan, J. Chen, S. Yao, W. Tao, and L. Nie, "An amperometric glucose biosensor based on glucose oxidase immobilized in electropolymerized poly $(o$-aminophenol $)$ and carbon nanotubes composite film on a gold electrode," Analytical Sciences, vol. 21, no. 4, pp. 367-371, 2005.

[111] A. Curulli, F. Valentini, S. Orlanduci, M. L. Terranova, and G. Palleschi, "Pt based enzyme electrode probes assembled with Prussian Blue and conducting polymer nanostructures," Biosensors and Bioelectronics, vol. 20, no. 6, pp. 1223-1232, 2004.

[112] A. Callegavi, S. Cosnier, M. Marcaccio et al., "Functionalised single wall carbon nanotubes/polypyrrole composites for the preparation of amperometric glucose biosensors," Journal of Materials Chemistry, vol. 14, no. 5, pp. 807-810, 2004.

[113] M. Trojanowicz and A. Miernik, "Bilayer lipid membrane glucose biosensors with improved stability and sensitivity," Electrochimica Acta, vol. 46, no. 7, pp. 1053-1061, 2001.

[114] S. Myler, F. Davis, S. D. Collyer, and S. P. J. Higson, "Sonochemically fabricated microelectrode arrays for biosensorspart II: modification with a polysiloxane coating," Biosensors and Bioelectronics, vol. 20, no. 2, pp. 408-412, 2004.

[115] F. He, Y. Tang, M. Yu, S. Wang, Y. Li, and D. Zhu, "Fluorescence-amplifying detection of hydrogen peroxide with cationic conjugated polymers, and its application to glucose sensing," Advanced Functional Materials, vol. 16, no. 1, pp. 91-94, 2006.

[116] A. Arslan, S. Kiralp, L. Toppare, and Y. Yagci, "Immobilization of tyrosinase in polysiloxane/polypyrrole copolymer matrices," International Journal of Biological Macromolecules, vol. 35, no. 3-4, pp. 163-167, 2005.

[117] C. Védrine, S. Fabiano, and C. Tran-Minh, "Amperometric tyrosinase based biosensor using an electrogenerated polythiophene film as an entrapment support," Talanta, vol. 59, no. 3, pp. 535-544, 2003.

[118] A. E. Böyükbayram, S. Kiralp, L. Toppare, and Y. Yağci, "Preparation of biosensors by immobilization of polyphenol oxidase in conducting copolymers and their use in determination of phenolic compounds in red wine," Bioelectrochemistry, vol. 69, no. 2, pp. 164-171, 2006.

[119] L. Jiang, H. K. Jun, Y. S. Hoh, J. O. Lim, D. D. Lee, and J. S. Huh, "Sensing characteristics of polypyrrole-poly(vinyl alcohol) methanol sensors prepared by in situ vapor state polymerization," Sensors and Actuators B, vol. 105, no. 2, pp. 132-137, 2005.

[120] M. A. Rahman, D. S. Park, and Y. B. Shim, "A performance comparison of choline biosensors: anodic or cathodic detections of $\mathrm{H}_{2} \mathrm{O}_{2}$ generated by enzyme immobilized on a conducting polymer," Biosensors and Bioelectronics, vol. 19, no. 12, pp. 1565-1571, 2004.
[121] J. Kan, X. Pan, and C. Chen, "Polyaniline-uricase biosensor prepared with template process," Biosensors and Bioelectronics, vol. 19, no. 12, pp. 1635-1640, 2004.

[122] J. Haccoun, B. Piro, V. Noël, and M. C. Pham, "The development of a reagentless lactate biosensor based on a novel conducting polymer," Bioelectrochemistry, vol. 68, no. 2, pp. 218-226, 2006.

[123] P. N. Bartlett, E. Simon, and C. S. Toh, "Modified electrodes for NADH oxidation and dehydrogenase-based biosensors," Bioelectrochemistry, vol. 56, no. 1-2, pp. 117-122, 2002.

[124] P. Asberg and O. Inganas, "Biomolecular and organic electronics," Biosensors and Bioelectronic, vol. 19, pp. 199-207, 2003.

[125] K. Grennan, A. J. Killard, and M. R. Smyth, "Chemically polymerized polyaniline films for the mass-production of biosensor devices," Electroanalysis, vol. 17, no. 15-16, pp. 1360-1369, 2005.

[126] J. Jia, B. Wang, A. Wu, G. Cheng, Z. Li, and S. Dong, "A method to construct a third-generation horseradish peroxidase biosensor: self-assembling gold nanoparticles to three-dimensional sol-gel network," Analytical Chemistry, vol. 74, no. 9, pp. 2217-2223, 2002.

[127] O. Ngamna, A. Morrin, S. E. Moulton, A. J. Killard, M. R. Smyth, and G. G. Wallace, "An HRP based biosensor using sulphonated polyaniline," Synthetic Metals, vol. 153, no. 1-3, pp. 185-188, 2005.

[128] B. Zhou, R. Sun, X. Hu et al., "Facile interfacial electron transfer of hemoglobin mediated by conjugated polymers," International Journal of Molecular Sciences, vol. 6, no. 12, pp. 303-310, 2005.

[129] A. Lindgren, T. Ruzgas, L. Gorton et al., "Biosensors based on novel peroxidases with improved properties in direct and mediated electron transfer," Biosensors and Bioelectronics, vol. 15, no. 9-10, pp. 491-497, 2000.

[130] Z. Dai, S. Liu, and H. Ju, "Direct electron transfer of cytochrome c immobilized on a NaY zeolite matrix and its application in biosensing," Electrochimica Acta, vol. 49, no. 13, pp. 2139-2144, 2004.

[131] S. Brahim, D. Narinesingh, and A. Guiseppi-Elie, "Polypyrrole-hydrogel composites for the construction of clinically important biosensors," Biosensors and Bioelectronics, vol. 17, no. 1-2, pp. 53-59, 2002.

[132] D. G. Bijanowska, M. Dawgul, and W. Torbicz, "Comparison of urea determination in biological samples by enfets based on $\mathrm{pH}$ and $\mathrm{pNH}_{4}$ detection," Sensors, vol. 3, no. 6, pp. 160165, 2003.

[133] A. Zhang, Y. Hou, N. Jaffrezic-Renault, J. Wan, A. Soldatkin, and J. M. Chovelon, "Mixed urease/amphiphile LB films and their application for biosensor development," Bioelectrochemistry, vol. 56, no. 1-2, pp. 157-158, 2002.

[134] A. V. Rebriiev and N. F. Starodub, "Enzymatic biosensor based on the ISFET and photopolymeric membrane for the determination of urea," Electroanalysis, vol. 16, no. 22, pp. 1891-1895, 2004.

[135] M. R. Pinto and K. S. Schanze, "Amplified fluorescence sensing of protease activity with conjugated polyelectrolytes," Proceedings of the National Academy of Sciences of the United States of America, vol. 101, no. 20, pp. 7505-7510, 2004.

[136] A. N. Ivanov, G. A. Evtugyn, L. V. Lukachova et al., "New poly aniline-based potentiometric biosensor for pesticides detection," IEEE Sensors Journal, vol. 3, no. 3, pp. 333-340, 2003.

[137] M. A. Rahman, D. S. Park, S. C. Chang, C. J. McNeil, and Y.-B. Shim, "The biosensor based on the pyruvate 
oxidase modified conducting polymer for phosphate ions determinations," Biosensors and Bioelectronics, vol. 21, no. 7, pp. 1116-1124, 2006.

[138] F. Qu, M. Yang, J. Jiang, G. Shen, and R. Yu, "Amperometric biosensor for chorine based on layer-by-layer assembled functionalized carbon nanotube and polyaniline multilayer film," Analytical Biochemistry, vol. 344, no. 1, pp. 108-114, 2005.

[139] O. A. Biloivan, S. V. Verevka, S. V. Dzyadevych et al., "Protein detection based on microelectrodes with the $\mathrm{PPy}[3,3-\mathrm{Co}(1,2-$ $\left.\left.\mathrm{C}_{2} \mathrm{~B}_{9} \mathrm{H}_{11}\right)\right] 2$ solid contact and immobilized proteinases: preliminary investigations," Materials Science and Engineering C, vol. 26, no. 2-3, pp. 574-577, 2006.

[140] D. Lee and T. Cui, "Low-cost, transparent, and flexible singlewalled carbon nanotube nanocomposite based ion-sensitive field-effect transistors for $\mathrm{pH} / \mathrm{glucose}$ sensing," Biosensors and Bioelectronics, vol. 25, no. 10, pp. 2259-2264, 2010.

[141] Y. Tan, W. Deng, Y. Li et al., "Polymeric bionanocomposite cast thin films with in situ laccase-catalyzed polymerization of dopamine for biosensing and biofuel cell applications," Journal of Physical Chemistry B, vol. 114, no. 15, pp. 50165024, 2010.

[142] C. Xiao, X. Chu, B. Wu, H. Pang, X. Zhang, and J. Chen, "Polymerized ionic liquid-wrapped carbon nanotubes: the promising composites for direct electrochemistry and biosensing of redox protein," Talanta, vol. 80, no. 5, pp. 17191724, 2010.

[143] R. Haddad, S. Cosnier, A. Maaref, and M. Holzinger, "Non-covalent biofunctionalization of single-walled carbon nanotubes via biotin attachment by $\pi$-stacking interactions and pyrrole polymerization," The Analyst, vol. 134, no. 12, pp. 2412-2418, 2009.

[144] J. Xie, X. Feng, J. Hu, X. Chen, and A. Li, "Al ${ }^{3+}$ directed self-assembly and their electrochemistry properties of three-dimensional dendriform horseradish peroxidase/polyacrylamide/platinum/single-walled carbon nanotube composite film," Biosensors and Bioelectronics, vol. 25, no. 5, pp. 1186-1192, 2010.

[145] K. Min and Y. J. Yoo, "Amperometric detection of dopamine based on tyrosinase-SWNTs-Ppy composite electrode," Talanta, vol. 80, no. 2, pp. 1007-1011, 2009.

[146] M. Bhambi, G. Sumana, B. D. Malhotra, and C. S. Pundir, "An amperomertic uric acid biosensor based on immobilization of uricase onto polyaniline-multiwalled carbon nanotube composite film," Artificial Cells, Blood Substitutes, and Biotechnology, vol. 38, no. 4, pp. 178-185, 2010.

[147] A. Barik, P. R. Solanki, A. Kaushik et al., "Polyanilinecarboxymethyl cellulose nanocomposite for cholesterol detection," Journal of Nanoscience and Nanotechnology, vol. 10, no. 10, pp. 6479-6488, 2010.

[148] C. Dhand, P. R. Solanki, M. K. Pandey, M. Datta, and B. D. Malhotra, "Electrophoretically deposited polyaniline nanotubes based film for cholesterol detection," Electrophoresis, vol. 31, no. 22, pp. 3754-3762, 2010.

[149] C. Dhand, M. Das, G. Sumana et al., "Preparation, characterization and application of polyaniline nanospheres to biosensing," Nanoscale, vol. 2, no. 5, pp. 747-754, 2010.

[150] A. A. Ansari, G. Sumana, R. Khan, and B. D. Malhotra, "Polyaniline-cerium oxide nanocomposite for hydrogen peroxide sensor," Journal of Nanoscience and Nanotechnology, vol. 9, no. 8, pp. 4679-4685, 2009.

[151] C. Dhand, S. K. Arya, M. Datta, and B. D. Malhotra, "Polyaniline-carbon nanotube composite film for cholesterol biosensor," Analytical Biochemistry, vol. 383, no. 2, pp. 194199, 2008.

[152] P. Pandey, S. P. Singh, S. K. Arya, A. Sharma, M. Datta, and B. D. Malhotra, "Gold nanoparticle-polyaniline composite films for glucose sensing," Journal of Nanoscience and Nanotechnology, vol. 8, no. 6, pp. 3158-3163, 2008.

[153] Z. Matharu, G. Sumana, S. K. Arya, S. P. Singh, V. Gupta, and B. D. Malhotra, "Polyaniline langmuir-blodgett film based cholesterol biosensor," Langmuir, vol. 23, no. 26, pp. 1318813192, 2007.

[154] C. Dhand, S. P. Singh, S. K. Arya, M. Datta, and B. D. Malhotra, "Cholesterol biosensor based on electrophoretically deposited conducting polymer film derived from nano-structured polyaniline colloidal suspension," Analytica Chimica Acta, vol. 602, no. 2, pp. 244-251, 2007.

[155] S. Singh, P. R. Solanki, M. K. Pandey, and B. D. Malhotra, "Covalent immobilization of cholesterol esterase and cholesterol oxidase on polyaniline films for application to cholesterol biosensor," Analytica Chimica Acta, vol. 568, no. 1-2, pp. 126-132, 2006.

[156] K. Arora, G. Sumana, V. Saxena et al., "Improved performance of polyaniline-uricase biosensor," Analytica Chimica Acta, vol. 594, no. 1, pp. 17-23, 2007.

[157] S. K. Sharma, R. Singhal, B. D. Malhotra, N. Sehgal, and A. Kumar, "Lactose biosensor based on LangmuirBlodgett films of poly(3-hexyl thiophene)," Biosensors and Bioelectronics, vol. 20, no. 3, pp. 651-657, 2004.

[158] S. K. Sharma, R. Singhal, B. D. Malhotra, N. Sehgal, and A. Kumar, "Biosensor based on Langmuir-Blodgett films of poly(3-hexyl thiophene) for detection of galactose in human blood," Biotechnology Letters, vol. 26, no. 8, pp. 645-647, 2004.

[159] R. Singhal, A. Chaubey, K. Kaneto, W. Takashima, and B. D. Malhotra, "Poly-3-Hexyl Thiophene Langmuir-Blodgett Films for Application to Glucose Biosensor," Biotechnology and Bioengineering, vol. 85, no. 3, pp. 277-282, 2004.

[160] A. Chaubey, K. K. Pande, and B. D. Malhotra, "Application of polyaniline/sol-gel derived tetraethylorthosilicate films to an amperometric lactate biosensor," Analytical Sciences, vol. 19, no. 11, pp. 1477-1480, 2003.

[161] S. K. Arya, P. R. Solanki, R. P. Singh, M. K. Pandey, M. Datta, and B. D. Malhotra, "Application of octadecanethiol self-assembled monolayer to cholesterol biosensor based on surface plasmon resonance technique," Talanta, vol. 69, no. 4, pp. 918-926, 2006. 


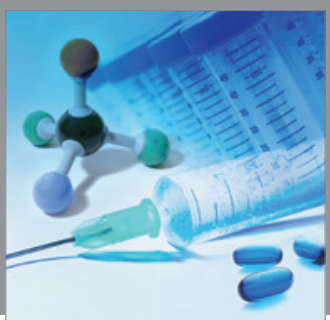

International Journal of

Medicinal Chemistry

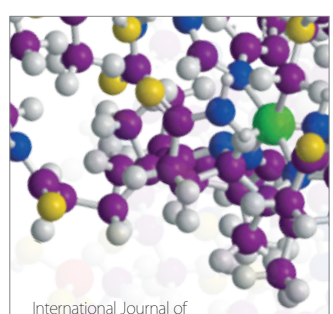

Carbohydrate Chemistry

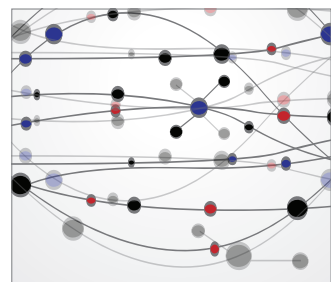

The Scientific World Journal
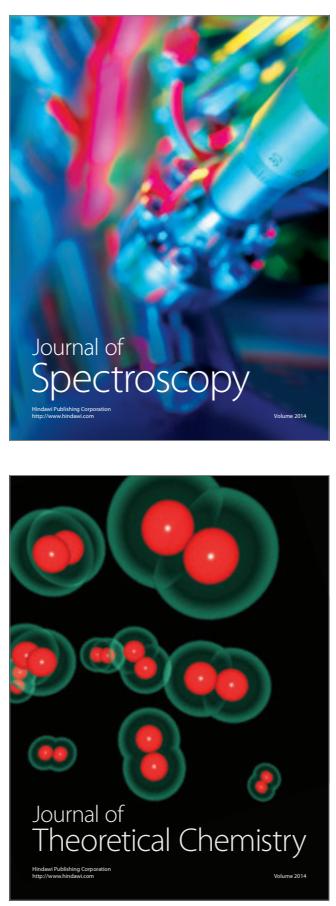
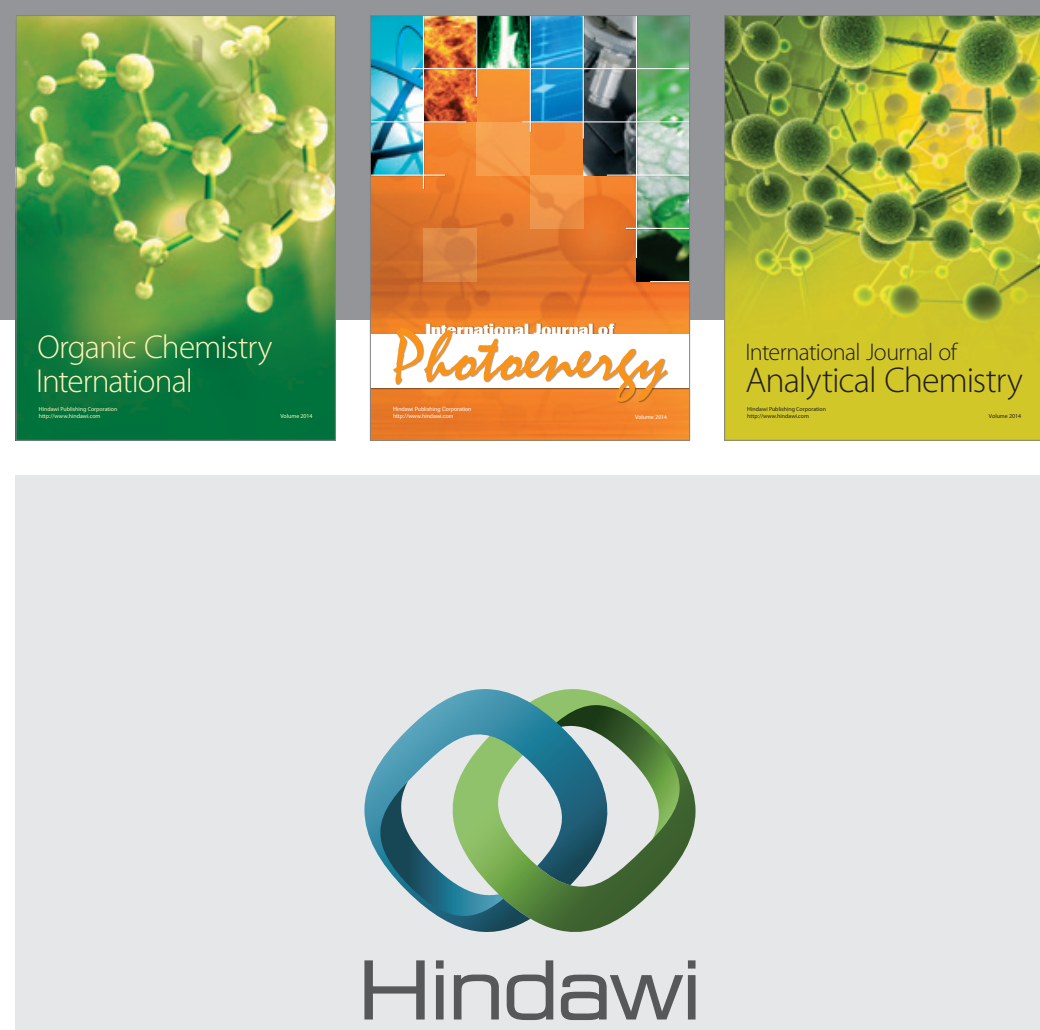

Submit your manuscripts at

http://www.hindawi.com
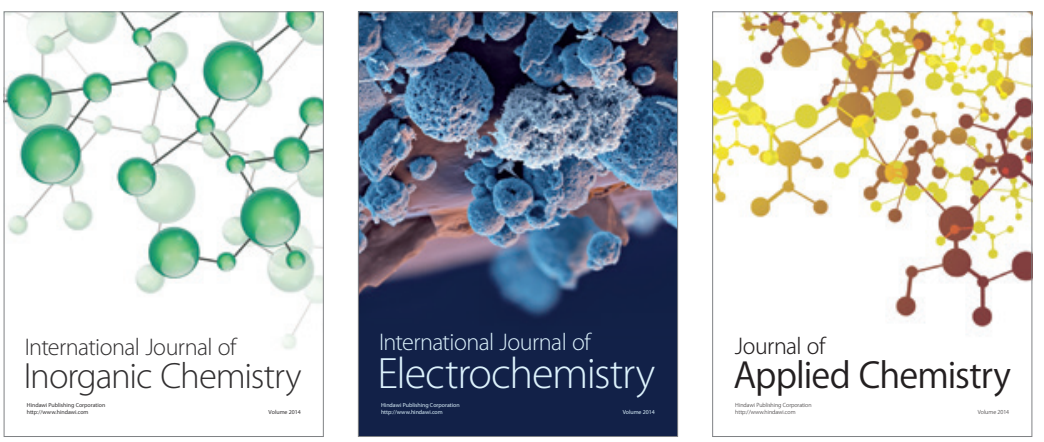

Journal of

Applied Chemistry
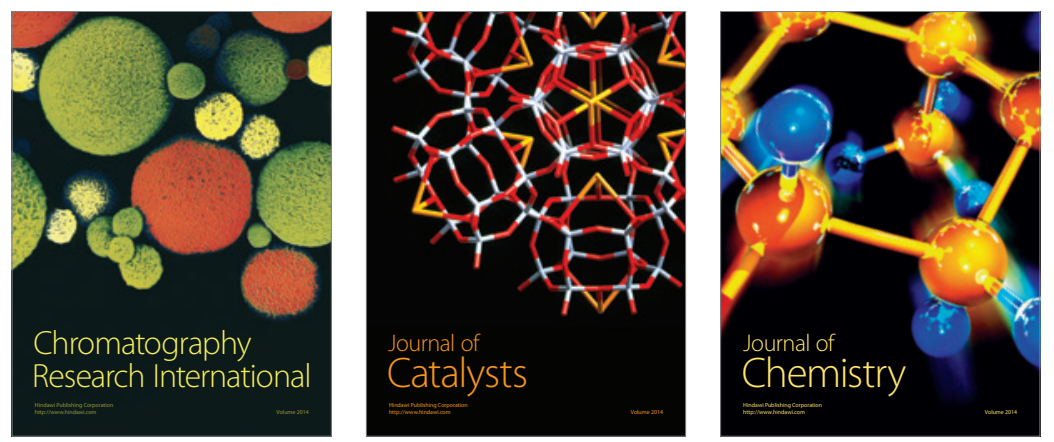
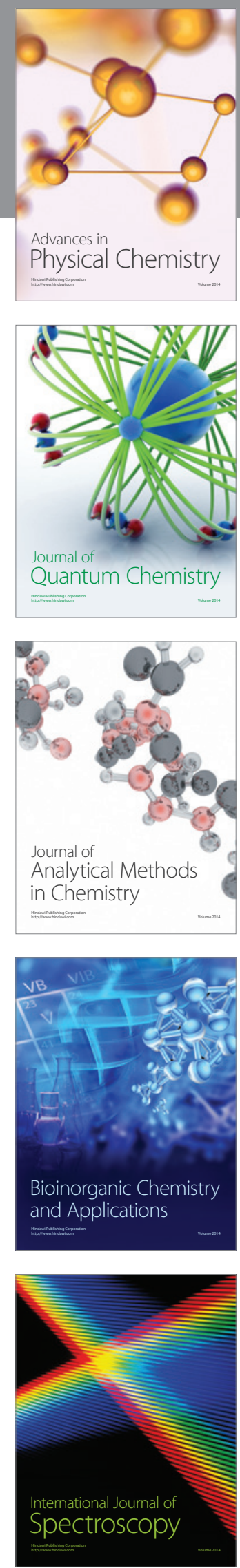